\title{
Organizing the Unexpected: How Civil Society Organizations Dealt with the Refugee Crisis
}

\author{
Michael Meyer $^{1}$ (D) Ruth Simsa ${ }^{1}$
}

Published online: 5 November 2018

(C) The Author(s) 2018

\begin{abstract}
The capability of organizations to respond to unexpected events has been investigated from different theoretical angles: organizational learning, improvisation, ambidexterity, resilience, to name but a few. These concepts, however, hardly ever refer to structural characteristics. Against this backdrop, the aim of this paper is twofold. First, based on systems and organizational learning theory, it will theoretically link the characteristics of organizational structure with organizational responses to unexpected external jolts, thus contributing to better understand the reactions of organizations to the unexpected. Second, it will empirically illustrate the relation of organizational structure with organizational responses by investigating how Civil Society Organizations (CSOs) in Austria reacted to the unexpected inflow of refugees from Central Europe. In 2015, CSOs accepted a wide range of responsibilities and worked together with government entities to provide shelter, catering, and transport for almost one million refugees. Based on participant observations during operation, in-depth interviews (2015 and 2016) and focus groups with decision-makers (2017), we will sketch three longitudinal case studies of organizations with very different structures, concentrating on the processes and operations they developed during the crisis. Our findings show that their responses are closely related to their structure, specifically to the flexibility and the stability of structural elements. Remarkable changes took place in all
\end{abstract}

Michael Meyer

Michael.Meyer@wu.ac.at

Ruth Simsa

Ruth.Simsa@wu.ac.at

1 WU Vienna (Vienna University of Economics and Business), Vienna, Austria organizations investigated. Initial responses and first structural changes occurred mainly where the structure already allowed for flexibility. Yet in the long run, the adaptations also impacted the stable structural elements.

Keywords Organizational flexibility · External jolts . Refugees $\cdot$ Resilience $\cdot$ Systems theory

\section{Introduction}

How do organizations respond properly to unexpected shocks and jolts? These questions have been discussed from different theoretical angles: organizational learning (Argyris and Schön 1978, 1996), dynamic capabilities (Eisenhardt and Martin 2000; Zollo and Winter 2002), organizational ambidexterity (Gibson and Birkinshaw 2004; He and Wong 2004), organizational improvisation (Moorman and Miner 1998; Pina e Cunha et al. 2015), and more recently organizational resilience (Lissack and Letiche 2002; Sutcliffe and Vogus 2003; Välikangas 2010). Another strand of the literature analyzes how organizations handle disasters and hazards (e.g., Grothe-Hammer and Berthod 2017; Kreps and Bosworth 1993; Lindell 2013). All these concepts emphasize organizational capabilities and processes of learning and adaptation, yet rarely refer to organizational structure.

The goal of the study is to analyze and discuss how responses of organizations are related to structural characteristics. In our understanding, structure is more than positions in an organizational chart. It embraces all devices that allocate, coordinate, and supervise activities directed toward the achievement of organizational aims (Pugh et al. 1968). Based on systems theory, the organizational learning framework and an empirical investigation, we relate 
organizations' responses to structural preconditions, in particular, to their redundancy and variety. The "unexpected" refers to a relevant change in an organization's environment that, for different reasons, had not been anticipated but required organizational reactions. Environmental jolts are defined as transient perturbations whose effects on organizations are disruptive and potentially inimical (Meyer 1982). Consequently, variations of structures are necessary. Likewise, to safeguard organizational identity and capacity for action, some structural elements must be retained. For dealing with this balance between stability and flexibility in stressful situations, social systems theory is particularly useful as it refers to the crucial importance of redundancy and variety for understanding organizations' decisions (Luhmann 1984, 1988, 2003).

We illustrate our theoretical assumptions with an empirical study of Civil Society Organizations (CSOs) in the so-called refugee crisis of 2015/16 in Austria. By spontaneously offering a wide range of services to refugees, CSOs had to deal with unforeseen and severe changes in their environment. Based on their main domains of redundancy, three different organizations were selected to study organizational changes and non-changes, and to relate the findings to our theoretical concept.

Following Luhmann's (1988) model, we conceptualize organizational structure as decision premises in three dimensions: programs, communication channels, and persons. We assume that organizations' reactions toward the unexpected are related to their flexibility and stability in these dimensions. We further draw on organizational learning theory and its different levels of learning (e.g., Argyris and Schön 1978; Bateson 1972; Chiva and Habib 2015). Choosing systems theory as theoretical basis has specific methodological implications: Communications and decisions rather than actions must be the relevant research objects, applying operative constructivism without claim of objectivity and an exploratory attitude toward distinctions regarded as relevant by the respective system instead of testing a hypothesis (Besio and Pronzini 2011).

The remainder of this paper is organized as follows: In the next chapter, we summarize prior research on organizational responses to disasters, crises, and external jolts. We then elaborate on systems theory, describing its understanding of autopoiesis, organizational structure, and particularly, the forms of decision premises that help organizations balance redundancy and variety. For developing our analytical frame, we will then amalgamate concepts from systems theory with organizational learning. After sketching out the empirical context, we present the findings from our three longitudinal case studies. Finally, we discuss our findings and argue how they might inspire further research.

\section{Literature Review}

Organizations' capabilities to deal with abrupt changes in their environment have been investigated from different theoretical angles. The literature on strategic management developed the concepts of dynamic capabilities (Eisenhardt and Martin 2000) and ambidexterity (Gibson and Birkinshaw 2004). Both suggest that organizations need to balance between routine operations and innovative activities, informed by March's (1991) basic distinction between exploitation and exploration. In research on organizational resilience (Hamel and Valikangas 2003; Välikangas 2010; Weick and Sutcliffe 2011), the question is rather how organizations can undergo deep change without or prior to a crisis, e.g., making their structure more robust or creating a culture that helps them to adapt.

In the organizational learning literature (Argyris and Schön 1978, 1996; Fiol and Lyles 1985), the question arises how organizations can learn from disasters and other rare events (Cooke and Rohleder 2006; Starbuck 2009; Starbuck and Farjoun 2009; Twigg and Steiner 2002). Empirical research on emergency and disaster response organizations (e.g., Carley and Harrald 1997; GrotheHammer and Berthod 2017), e.g., in US coal mining (Madsen 2009), the NASA space shuttle accidents, airplane crashes, and similar significant accidents (e.g., Cooke and Rohleder 2006), rather questions the probability of learning from unique events (Starbuck 2009). Nevertheless, unexpected jolts may work as unfreezing events for organizations, triggering significant organizational change (Carley and Harrald 1997).

In their typology of organized responses to disaster, Kreps and Bosworth (2007) distinguish between tasks and structural responses: Tasks may be regular or irregular; structure can be old or new. They differentiate between four types of responses: (1) established, i.e., regular tasks based on old structure, (2) extending, i.e., non-regular tasks based on old structure, (3) expanding, i.e., regular tasks based on new structure, and (4) emergent, when non-regular tasks are executed with a new structure. The authors further argue that organized responses require external recognition as a purposive entity (domain), clarity about a division of labor (tasks), human and material resources and the conjoined actions of both individuals and larger social units (organizations). Their approach has some similarities with ours, yet lacks assumptions how those different responses can be explained by prior organizational structure.

Based on research on how organizations process and institutionalize external jolts to sustainable change (Greenwood and Hinings 1987, 1988, 1996), Laughlin (1991) developed four types of organizational reactions to 
environmental disturbances: rebuttal, reorientation, colonialization, and evolution. (1) Rebuttal means a temporal shift to an alternative design archetype and a return to the original as the disturbance vanishes. (2) Reorientation means accepting and integrating the disturbance into newly shaped designs and subsystems. (3) In colonialization, not only designs and subsystems change, but also the interpretive (cognitive) schemes. (4) In evolution, the reformulation of interpretive schemes leads to fundamental reshaping.

Concepts of organizational bricolage and improvisation (Barrett 1998; Hadida et al. 2015; Moorman and Miner 1998; Pina e Cunha et al. 2015) have been strongly inspired by the performing arts (Cornelissen 2006). Moorman and Miner define improvisation "as the degree to which composition and execution converge in time" (Moorman and Miner 1998). High levels of procedural memory thus contribute to coherent but less novel improvisation; high levels of declarative memory contribute to coherent and novel action (Moorman and Miner 1998). Thus, shared knowledge within an organization can be supportive for coherence and novelty.

There is also a vast literature on emergency management. During operation, scenario planning and conditional programs often play a crucial role, still providing some flexibility in operation in contingent situations (GrotheHammer and Berthod 2017). In a study of two emergency organizations dealing with a hurricane, Carley and Harrald (1997) show that teams with personnel empowered to act on basis of their experience outperform teams with personnel following standard operational procedures. Furthermore, decentralized organizations with more autonomous teams outperform more hierarchical organizations and seniority and experience play an important role.

Results yielded by case studies on SWAT teams and film crews point in a similar direction (Bechky and Okhuysen 2011). Whenever surprises disrupt expectations, actors respond by engaging in problem solving and trying to recreate the order they have lost. They do so in manifold practices of organizational bricolage: role shifting, reorganizing routines, reordering work, shared task knowledge, and common workflow expectations (Bechky and Okhuysen 2011). For teams dealing with unexpected incidents, three major success factors can be identified (Oliver and Roos 2003): (1) increasing presence, (2) creating a context for a shared and emotionally grounded identity, (3) developing a shared set of guiding principles for action. Some further successful patterns are stockpiling of supplies and tools. In this respect, social and cognitive processes play a crucial role, based on a processual memory (Moorman and Miner 1998) and collective knowledge of syntax and grammar (Barrett 1998).
To sum up, prior research has contributed many concepts that explain how organizations deal with external jolts, and which preconditions facilitate appropriate responses. Findings are partly contradictory: On the one hand, the literature recommends loosely coupled units and autonomous teams. Loose coupling helps the organization to remain functional under stress, as damage can be more easily isolated (Välikangas 2010). On the other hand, tightly coupled hierarchical organizations with an incidentcommand system are seen as extremely viable in stressful situations, as long as they guarantee sufficient slack for improvisation (Bigley and Roberts 2001). We will explain how both modes of structure have their merits in specific situations. Yet, there is still a significant gap in how prior decisions that have condensed in structural preconditions frame the paths of organizational responses.

\section{Theory}

Luhmann's theory with its focus on variety and redundancy provides an appropriate framework for understanding the interplay between structure, stability, and flexibility in organizations (Luhmann 1988, 2000, 2003). It explains this balance by autopoietic and recursive processes (Bakken and Hernes 2003), hereby focusing on communication (Clegg 2015). We will align it with organizational learning (Luhmann 2000: 74f.), though it doubts that organizations simply learn by reacting on external triggers, as both their perception of their environment and their options for reacting are shaped by internal structures. Recently, systems theory has gained more attention though empirical studies based on this theory are scarce. Hendry and Seidl draw on the concept of an "episode" to explore organizational change (Hendry and Seidl 2003). Grothe-Hammer and Berthod (2017) study disaster management of a German city, focusing on spatial and conditional programs. Dobusch and Schoeneborn (2015) analyze how fluid social collectives such as internet communities accomplish organizationality based on the communicative constitution of organizations.

Luhmann decided to observe the social world as molded by social systems, which are assumed to operate autonomously, yet with interplay with other systems. Characterized as the difference between system and environment (Luhmann 2006), all social systems are seen as operationally closed networks of communications, based on clear boundaries to their environment. Guided by meaning, ${ }^{1}$ social systems reproduce themselves selectively, in an autopoietic way from elements previously filtered from an

\footnotetext{
${ }^{1}$ Introducing 'meaning' (Sinn in German), Luhmann relates to phenomenology of Edmund Husserl and Alfred Schütz on the
} 
over-complex environment (Luhmann 1998, 2012). They do so by applying communication codes or-in the case of organizations-decision premises that provide rules for appropriate communication and action which allow for continuity of the system's autopoiesis (Holmer-Nadesan 1997).

Autopoiesis is guided by the system's internal structures (Bakken and Hernes 2003; Luhmann 1998). This is not meant ontologically, but refers to the selection of elements, i.e., communications, by the system (Seidl and Becker 2006). Social systems observe their environment and react to it in a self-referential, operationally closed way, based on their internal structures. Thus, any forms of change are determined by the system itself. The environment produces noise and irritations which can only be transformed into information and further communication if they are "understood" as meaningful by the system (Ferreira 2014).

The basic elements of social systems are communications (Luhmann 1986). Organizations, however, are defined as specific social systems that consist of decisions, i.e., compact yet contingent communications, seen as choices among alternatives (Luhmann 2000). Decisions are thus the basic element of organizational self-production, and organizations can be understood as social systems "consisting of decisions, and making the decisions they consist of by the decisions they consist of" (Luhmann 1988).

Decisions are always contingent and related to inherent uncertainty (Schoeneborn 2011). Luhmann stresses their paradoxical nature. Decisions are a specific form of (compact) communication, which, more or less explicitly, not only convey the chosen alternatives but also a set of rejected alternatives (Luhmann 2000). To maintain their autopoiesis, organizations thus need structures, which “(...) limit the set of possible relations between communications and therefore transform contingency into a structured complexity" (Besio and Pronzini 2011). Therefore, decisions form decision premises for further decisions.

Structures are understood as internal rules and expectations that organize the relations within a social system. In organizations, decision premises form the organizational structure. In other words: Organizational structures are conditions for decisions that need not be verified when used for further decisions (Luhmann 2000). Luhmann points to three types of decision premises, which restrict the leeway for decisions, namely programs, personnel, and communication channels (Luhmann 2000: 222ff).

Footnote 1 continued

subjective and reflexive reconstruction of meaning as compared to intersubjective meaning (Schütz 1974).
Programs delineate the topics about which meaningful communication is possible. Programs usually contain objectives, strategies, mission statements, rules and guidelines, and also statutes, and planning documents to ensure that an organization cannot decide and communicate about everything in any way. They may be constructed as conditional programs-Grothe-Hammer and Berthod (2017) find that those programs are particularly relevant for disaster management-or as goals. They do not need to be explicitly formulated; organizational culture and history also form programmatic expectations. An emergency organization might regulate that warm food handed out to refugees must meet quality criteria or not, that all refugees are medically examined or not, that the provision of transport or rather a warm atmosphere has top priority.

Communication channels define relations between internal positions, but also to external actors. They delineate lines of command and accountability and regulate the social aspect of decision making, including hierarchies, organizational charts, reporting lines, task distribution, and all sorts of formal and informal super-/subordination that guides decision making. For example, these channels might regulate that only the head of operations or everyone may decide about services offered. An organization might rely more on presence, on formal functions or on informal networks of trust.

Persons refers to the way how an organization constructs individual actors (e.g., as soldiers, heroes, geeks) and how important individual actors are. How important is it for future decisions which individual actor fills a position? Expectations and attributions to individual actors thus form decision premises. Organizations, for example, might expect high degrees of motivation and dedication and thus give ample room to an individual for action; they might rely strongly on specific persons, like founders, or give space to everybody who shows a strong presence; the decision to include new volunteers might be based on trust or on specific training requirements, etc.

Luhmann also distinguishes between the normative and the cognitive side of structure (see Fig. 1): Normative components are not decided explicitly; they remain widely latent and are less subject to learning. They constitute organizational culture. (Luhmann 2000).

These three types of decision premises constitute organizational structure. Apart from selecting decisions, structure also balances redundancy and variety in organizations (Luhmann 1988, 1998). Redundancy means the structural limitation of decisions to reduce complexity and allow for predictability and regularity. Redundancy provides for an organization's consistency and secures its self-reproduction. Strict programs, for example, contribute to a high redundancy of tasks. Likewise, clear hierarchies or welldefined responsibilities will secure redundancy regarding 
Fig. 1 Components of organizational structure in three dimensions

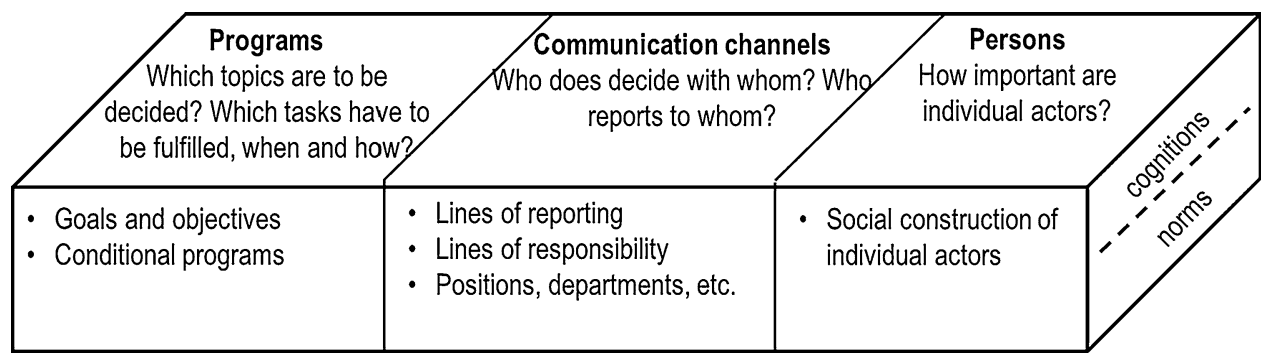

social relations. Variety means increasing the internal complexity by permitting a broader range of different decisions. Vague rules and guidelines, for example, allow for a high variety of tasks, while openness permitting everyone to participate allows for variety of ideas and relations. Therefore, redundancy contributes to stability and variety to flexibility.

Usually, organizations keep a dynamic balance between stability and flexibility. If variety prevails, boundaries will blur and organizations will dissolve. If redundancy prevails, organizations become unable to adapt. There is a dialectic relationship between self-maintenance and change: "Structural change requires self-maintenance." (Luhmann 1984: 474). Organizations can somehow juggle with different means to ensure the appropriate balance. Thus, for example, strict procedures for task achievement allow for variability regarding persons-in assembly lines persons can be exchanged easily. When tasks cannot be defined clearly, who holds specific positions becomes important. Assigning important functions to people with clearly defined preferences may be a functional equivalent to narrow programs; and an influential history of an organization (program) might ensure that only a specific type of person is selected for specific positions. "The system constantly oscillates between constraining and extending decision possibilities and in this way secures its own autopoiesis." (Luhmann 2005: 95) Thus, structure either narrows or broadens flexibility with respect to programs, communication channels, and persons.

Given that organizational structures are perceived as conditions for further decisions and that organizations use different combinations in the balance of redundancy and variety, these combinations, too, have to deal with the paradox that alternative decisions can always be made (Ferreira 2014). This paradox is somewhat mitigated by perceiving and treating some structures (the redundant ones) as less open to decisions, as taken for granted, at least temporarily.

Systems theory instructs us that adaptations of structure will only take place if they have been observed as inappropriate. Then, again, organizations firstly relax those premises that have already allowed for some flexibility. In a similar vein, the literature on organizational learning suggests a cascade of learning (e.g., Argyris and Schön 1978; Fiol and Lyles 1985). Based on the work of Gregory Bateson (1972), authors distinguish between different levels of learning: Zero learning is a merely conditioned response. First-order learning (single loop, adaptive learning) means correcting errors of choices within a set of alternatives. Second-order learning (double-loop, reflective or generative learning) denotes a change in the process of learning itself and a change in the set of alternatives from which choice is made (Chiva and Habib 2015: 359f). Third-order learning (triple loop or deutero learning) finally focuses on the competency to effectively utilize single- and double-loop learning.

Those levels of learning are widespread in the OL-literature (see Chiva and Habib 2015), and encompass personal experiences and cognitions, shared language and cognitive maps, shared understandings and attributions, rules and procedures (Crossan et al. 1999; Crossan et al. 2011) ranging from intuition, interpretation, integration to institutionalization. Thus, it spans from the individual via the group to the organizational level (Crossan et al. 1999). Only in the stage of institutionalization, learning affects routines, rules, and procedures-thus addressing organizational structure.

Our analytical frame is also inspired by Kreps and Bosworth (2007) who differentiate between regular and non-regular tasks and old and new structure. We apply a wider definition of structure beyond a mere stratification and clustering of positions. This implies structural change in any case of non-regular decisions. Likewise, Laughlin (1991) interprets organizational structure and perception as intertwined. Again, organizations will firstly try to adapt to disturbances without fundamentally changing their structure and interpretive schemes (rebuttal), in case of failure they will tend to change interpretive schemes which then leads to a change in design archetypes (reorientation or evolution); or they will directly alter their structural archetypes, leading to new interpretive schemes as a consequence (colonization). Overall, according to Greenwood and Hinings (1993), any major organizational change, or passage between archetypes, is less common than inertiaarchetype stability. 
Within the frame of systems theory, we focus on decisions and decision premises, as individuals' cognition is seen as external to albeit influenced by organizational structure. Therefore, we slightly reformulate the levels of learning: In our understanding, (1) first-order learning concentrates on single decisions within the perceived frame of decision premises. (2) Second-order learning denotes an adaptation of decision premises in those domains that allow for variety and flexibility. (3) Third-order learning, eventually, denotes a change in decision premises that have been perceived as stable safeguards of redundancy.

To sum up, our theoretical considerations suggest an analytical frame that distinguishes between three types of responses to unexpected jolts: First, organization may react within the frame of their decision premises. Second, they may adapt those domains that already allow for flexibility. Third, they may alter those domains within their decision premises that have been pillars of stability. Only the latter will bring long-term organizational change. To learn more about these levels of responses, we empirically analyzed the responses of three Civil Society Organizations (CSOs) to the so-called refugee crisis of 2015 .

\section{Empirical Context, Methods, and Cases}

The so-called refugee crisis of 2015 provides the empirical background of our analysis. On 31 August, some 8000 refugees crossed the Austrian border after the Hungarian government temporarily opened its borders. After this brief release, the humanitarian conditions for the refugees became unbearable in Hungary, and on 4 September, the situation escalated. Hundreds of refugees started to walk from Budapest toward the Austrian border. The Austrian chancellor decided after an agreement with the German chancellor to open the borders. Within $48 \mathrm{~h}$, approximately 15,000 refugees crossed the border. Between September and December 2015, almost one million refugees from the Middle East streamed through Austria. About 90,000 applied for asylum in Austria. Throughout autumn, over 1.3 million overnight stays were counted in the 73 emergency shelters in the city of Vienna alone (Kornberger et al. 2018). From February 2016 onwards, the influx was dramatically reduced by controversial political measures.

Public authorities alone were not capable of coping with the challenge. The vacuum was filled by civil society activities. CSOs thus played a crucial role in handling the situation. Without the numerous CSOs, without the thousands of volunteers, and without the public pressure exerted by them, the country would not have been able to provide shelter, transport and food for so many people (Simsa 2017). Though many early warnings had indicated this migration through Central Europe (Syria descending more and more into civil war; widely chaotic warlike situations in Iraq and Afghanistan), the situation was exacerbated by a cut in funding for the refugee camps in the Middle East and, for many CSOs, the migration came as an unexpected jolt.

We started to collect observational and interview data on how different CSOs dealt with this situation in 2015. For this specific study, our research was motivated theoretically and inspired by the distinct structural forms of three CSOs that were in the limelight in autumn 2015. Based on about $60 \mathrm{~h}$ of participant observation and $60 \mathrm{~h}$ of one-to-one interviews, we chose three CSOs to illustrate our theoretical ideas: the Red Cross, Caritas Vienna, and Train-of-Hope. We selected these CSOs for theoretical reasons, as they show very distinct organizational structures regarding their basis of redundancy and flexibility. For characterizing the CSOs, we also analyzed organizational charts, mission statements, policy papers, and standard operational procedures as far as available.

Austrian Red Cross is one of Austria's largest CSOs in the field of emergency relief and ambulance services. It has more than 70,000 volunteers and more than 10,000 paid employees. Like many CSOs in Austria, it is organized federally, and during the critical time in 2015, most of its nine federal organizations were involved. Red Cross has well-established plans for emergency aid in natural disasters. It has hierarchical structures, following a commandand-control model (Whittaker et al. 2015). Its volunteers are well trained as paramedics and officers. During the first weeks, the inflow of refugees was just another case of emergency for the organization. It erected tents and provided the refugees with first aid, catering, medical, and sanitary services at the borders. Also, soon they started to run large emergency shelters for refugees.

Caritas Vienna belongs to one of the largest CSOs in social services. Caritas employs a few thousand paid employees and more than 10,000 volunteers. It is a highly diversified social service organization with tasks ranging from elderly care to the aid for the homeless and women affected by domestic violence. Caritas is also one of the strongest advocacy CSOs for the most vulnerable. The organization is formally structured but-depending on the respective task fields-allows for different degrees of selforganization and has rather flat hierarchies. During the crisis, the organization performed many tasks: They established emergency shelters, provided supplies to refugees at train stations, organized private accommodations, childcare, and legal advice.

Train-of-Hope is a grassroots organization that emerged during the crisis from a group of befriended students that had met and built up trust in the context of student's protests. It showed a high degree of participation and spontaneity, rejected hierarchical leadership structures 
and focused on rather narrow tasks. Train-of-Hope provided refugees with initial assistance at Vienna central railway station; it worked self-organized over months and-contrary to the other two organizations-without public funding. During that time, Train-of-Hope founded an association with six board members who were responsible for the coordination of activities, and established several task forces for specific areas of emergency aid (e.g., catering, support for children). Train-of-Hope also acquired many refugees as volunteers.

Beyond analyzing available documents, we utilized three different sources of qualitative data to avoid singlemethod bias and to allow for an open the research process (see Table 1). We collected data in 2015, 2016, and 2017:

1. In autumn 2015, we conducted 57 semi-structured, problem-centered interviews with political decision makers, CSO-managers, volunteers, refugees, and other actors involved, to get an encompassing picture of the situation. These data were generated during a larger-scale research project on the contribution of civil society during the refugee crisis. From these interviews, we selected 13 with respondents from the three CSOs under investigation. We also conducted $60 \mathrm{~h}$ of participatory observations, starting very early in September 2015 at those sites where the CSOs' operations took place, such as the railway stations in Vienna and refugee shelters. For this paper, we used five of these observation notes, mainly with a focus on the role of persons and communication channels, which both were well observable. Together with the documents, they served as a starting point for the further analysis.

2. In autumn 2016, we collected a second round of three interviews with the top executives of the three CSOs. These interviews mainly focused on how the CSOs had changed in the course of the dramatic events since autumn 2015.

3. In autumn 2017, we conducted three focus group discussions with altogether eight representatives of the three CSOs. Again, we asked retrospectively what aspects had changed during the crisis, and if/how this has led to long-term changes. In each group, there was a top-level executive or (in the case of Train-of-Hope) a top decision maker, a unit head (not at Train-ofHope), and a person in charge of the operations at street level.

The eleven interviews and the three focus groups were transcribed. We combined inductive and deductive coding, thus integrated data-and theory-driven codes (Fereday and Muir-Cochrane 2006). The inductive coding followed main themes that emerged in the interviews, e.g., activities, management decisions, problems and coping strategies, differences between involved organizations. Further, following a deductive coding strategy (Miles et al. 2014), all textual data were coded according to main themes. We particularly looked for decision premises: (1) programs (standards, criteria, goals, strategies, and conditional programs such as emergency plans and standard operational procedures), (2) communication channels (hierarchy, positions and their relations, departments, division of labor, and responsibility), and (3) persons (particular contributions of single actors in terms of resources, capabilities, and engagement).

The coding process focused on relevant decisions taken by the CSOs (Boyatzis 1998). By collecting the observations and descriptions that our respondents regarded as relevant, we followed suggestions of systems theory to view the researcher as a second-order observer (Seidl and Becker 2006). By asking more than one respondent per CSO at different points of time, by conducting group discussions and enriching our analyses with documents and observations, we hope to minimize key informant bias (Eisenhardt and Graebner 2007; Onwuegbuzie and Leech 2007). Choosing systems theory has methodological implications: Communications, respectively, decisions and not actions must be the relevant research objects, applying operative constructivism without claim of objectivity and

Table 1 Sources of data and method of data collection elements for redundancy in the three selected CSOs

\begin{tabular}{|c|c|c|c|c|}
\hline Time & Collected data & Respondents & Selected & Respondents \\
\hline 2015 & $\begin{array}{l}57 \text { qualitative } \\
\text { interviews }\end{array}$ & $\begin{array}{l}\text { Decision makers, volunteers, } \\
\text { refugees }\end{array}$ & $\begin{array}{l}13 \text { qualitative } \\
\text { interviews }\end{array}$ & $\begin{array}{l}\text { Decision makers of the Red Cross, Caritas, Train-of- } \\
\text { Hope }\end{array}$ \\
\hline 2015 & $\begin{array}{l}11 \text { participant } \\
\text { observations }\end{array}$ & $\begin{array}{l}\text { Students and faculty members } \\
\text { volunteering }\end{array}$ & $\begin{array}{l}5 \text { observation field } \\
\text { notes }\end{array}$ & $\begin{array}{l}\text { Students volunteering for Red Cross, Caritas, Train- } \\
\text { of-Hope }\end{array}$ \\
\hline 2016 & $\begin{array}{l}3 \text { qualitative } \\
\text { interviews }\end{array}$ & Decision makers & $\begin{array}{l}3 \text { qualitative } \\
\text { interviews }\end{array}$ & $\begin{array}{l}\text { Decision makers of Red Cross, Caritas, Train-of- } \\
\text { Hope }\end{array}$ \\
\hline 2017 & 3 group discussions & 7 decision makers & 3 group discussions & $\begin{array}{l}3 \text { decision makers of Red Cross, } 3 \text { of Caritas, } 2 \text { of } \\
\text { Train-of-Hope }\end{array}$ \\
\hline
\end{tabular}


an exploratory attitude toward distinctions regarded as relevant by the respective system instead of testing hypothesis. "The ultimate reality is the reality of the system, which has to construct a network of observations while continuing to operate" (Besio and Pronzini 2011: 20).

We analyzed the data in four steps (see also Tables 3, 4, 5 and 6 in "Appendix" for a summary of steps and findings): (1) For yielding descriptions of prior structure, we started with documents (organizational charts, regulations, emergency plans) as far as available and matched them with reports from participant observation and the first round of interviews. (2) For grasping primary responses, we concentrate on observations and interviews that have been confirmed at least by two sources in 2015. (3) For structural changes over time, we relied mainly on the interviews in 2016, but triangulated them with the 2017 group discussions. (4) For longer lasting structural changes, we utilized the group discussions, concentrating on the areas of consensus between the participants.

\section{Findings}

For all organizations investigated, the massive inflow of refugees in 2015 was an unanticipated jolt. Even Red Cross and Caritas that had already started first preparations in summer did not expect such a massive influx. Civic engagement increased dramatically, including donations and volunteerism, the latter creating management challenges for CSOs (Simsa et al. 2018). Altogether, the immense humanitarian and logistical challenge was managed by a diverse, polycentric network of organizations, including political actors and CSOs. Especially at the beginning, CSOs carried the major burden of emergency relief activities. The three CSOs investigated started out from different organizational structures (see also Table 3 in "Appendix").

Red Cross' structure is hierarchical and incident-command oriented. Redundancy is guaranteed mainly by programs and communication channels: clear and sharply defined emergency plans, a similarly clear-cut schedule of responsibilities, hierarchies and a line of command, and well-defined rules for hiring, training, and deploying volunteers. Therefore, it is highly flexible in terms of the number of involved persons and capable to swiftly deliver in case of urgency. Whenever an emergency event happens, Red Cross teams are ready for action.

\footnotetext{
2 In our findings section, we report our observations of our respondents' observations. As a contribution to readability, we do not explicitly refer to that in any case. In our discussion section, we also add our interpretations.
}

Caritas at Caritas, redundancy is safeguarded by its strong, but broad mission statement-"We are here for people in need-all over the world and around the clock"-and the strategies derived from this mission. Further, for decades, Caritas has been known for its clear political standpoint on immigration (programs). The top management is widely autonomous, highly accepted within the organization, and the president displays charismatic leadership. Hence, redundancy is also secured by the top management and its values (persons).

Train-of-Hope this CSO started from scratch. At the very beginning of the refugee crisis, it was not an organization at all. Train-of-Hope's original pillars of redundancy were friendship relations among the core actors-and their physical presence (communication channels)-and its purpose (programs): "To offer help to refugees in a human and non-bureaucratic way." The decision to concentrate on one location also contributed to redundancy (program). Table 2 gives a summary of the organizations' decision premises that are particularly relevant for redundancy and variety.

From this starting point, we analyzed the initial responses of the organizations (see also Table 4 in "Appendix").

"Dealing with emergencies is in our DNA-we are used to that," (RC/2016) said a representative of the Red Cross. Yet even for the Red Cross, the challenge was described as unique in terms of size and urgency. It is well prepared to act spontaneously in sudden crises, but not to maintain these intensive activities over longer periods. "Then our emergency routines started to operate in a dimension we never had before, but still we were still able to handle this with standard routines." (FG/2017) Within a few weeks, the Red Cross not only deployed their regular well-trained enormous numbers of volunteers, but also their reserve army of volunteers they had built up since 2007. Thus, the Red Cross was well prepared, and the initial reaction was especially flexible regarding time and persons, facilitated by clear hierarchies: "We were lucky, whenever our commanders took control." (FG/2017) Likewise, a significant expansion of the working hours of the paid staff and volunteers demonstrated this flexibility. Redundant elements of organizational structure like emergency plans and control structures allowed for high flexibility in less rigid areas, such as the inclusion of new volunteers. Such rules were explicitly defended by the organization. Examples are the strict reactions to the unauthorized use of mobile radio devices by volunteers or the rather modest scope for selforganization of volunteers.

"We are not an emergency organization," (CA/2016) said a manager of Caritas. There was no emergency plan, and it was not even programmed that Caritas had to take responsibilities at all. Nevertheless, Caritas started with 
Table 2 Major elements for redundancy and variety in the three selected CSOs

\begin{tabular}{|c|c|c|c|c|c|c|}
\hline & \multicolumn{2}{|l|}{ Programs } & \multicolumn{2}{|l|}{ Communication channels } & \multicolumn{2}{|l|}{ Persons } \\
\hline & Redundancy & Variety & Redundancy & Variety & Redundancy & Variety \\
\hline $\begin{array}{l}\text { Red } \\
\text { Cross }\end{array}$ & $\begin{array}{l}\text { Mission, } \\
\text { emergency } \\
\text { plans }\end{array}$ & $\begin{array}{l}\text { Expanding working } \\
\text { hours of paid staff and } \\
\text { volunteers }\end{array}$ & $\begin{array}{l}\text { Hierarchy and line of } \\
\text { command recruitment } \\
\text { procedures for volunteers }\end{array}$ & & & $\begin{array}{l}\text { Large numbers of } \\
\text { volunteers can be } \\
\text { integrated quickly }\end{array}$ \\
\hline Caritas & $\begin{array}{l}\text { Mission, } \\
\text { strategy, } \\
\text { history }\end{array}$ & $\begin{array}{l}\text { Flexible goals derived } \\
\text { from the mission }\end{array}$ & Lines of reporting & $\begin{array}{l}\text { Swiftly } \\
\text { establishing } \\
\text { a new unit }\end{array}$ & $\begin{array}{l}\text { Top } \\
\text { management } \\
\text { team }\end{array}$ & $\begin{array}{l}\text { Openness for } \\
\text { volunteers }\end{array}$ \\
\hline $\begin{array}{l}\text { Train- } \\
\text { of- } \\
\text { Hope }\end{array}$ & $\begin{array}{l}\text { Purpose, } \\
\text { location }\end{array}$ & $\begin{array}{l}\text { Resources and tools } \\
\text { broad and flexible } \\
\text { range of activities }\end{array}$ & $\begin{array}{l}\text { Personal relationships (trust), } \\
\text { presence }\end{array}$ & $\begin{array}{l}\text { Lack of } \\
\text { formal } \\
\text { hierarchy }\end{array}$ & Founders & $\begin{array}{l}\text { Openness for } \\
\text { volunteers }\end{array}$ \\
\hline
\end{tabular}

emergency aid already in August 2015. In September 2015, the top management decided to take further action. Twenty paid employees were released from their regular jobs and transferred to a newly established unit, hundreds of volunteers followed. When the first refugees arrived at one of Vienna's train stations, this unit started to operate immediately: self-organized, without clear operational procedures and in a "learning by doing" mode. "As we saw that we would need emergency shelters, we built a new structure for that within a few days-without any clear details of how to do it" said a Caritas top manager (I5/2016), and "there was a readiness to partly skip the daily business and jump into this operation, there was the real Caritas feeling." (FG/2017) As redundancy was secured mainly by history, persons, mission, and strategy, Caritas utilized variety in terms of hierarchy and other communication channels. Those were rebuilt within a few days: Staff was shifted temporarily to the new unit; rules regarding hierarchy were abandoned. Suspending clear rules for their integration, now many volunteers were integrated spontaneously, sometimes even as team leaders or responsible for management tasks like the organization of schedules. "There were strategic decisions that didn't prove viable in operation, so we had to readjust permanently, very spontaneously." (FG/2017) This caused conflicts and disorientation, yet it was buffered by the strong commitment to the organizational mission, and the intense involvement of the top management.

Train-of-Hope started "with a table and few items of food and garments" but with "truckloads of personal concern and emotions-too many emotions" (TH/2016). It applied social media so professionally that it established a database of 6000 active volunteers within a few days. Yet, structure was chaotic, "after day six, the division of labor was not yet well-established." Thus, communication channels were very open, and very dependent on personal relationships. Only after a couple of weeks, volunteer management allowed for planning ahead at least for the next day. Volunteers were provided with to-do lists, but there was still much need and space for improvisation. Apart from the purpose, the location and the strong bonds between the core actors, Train-of-Hope is the case with least redundancy. Individuals acted very autonomously, ensuring a lot of flexibility in all dimensions. "There was no overall leadership, and at the beginning, no one supervised the whole operation." (FG/2017) Because of the absence of clear communication channels, physical presence was crucial: "Everyone who had an idea and convinced those around him could do it. If ten guys said ok, the idea can't be so bad." (FG/2017) Redundancy was further maintained by the strong purpose: "It's important that all work that has to be done is done and not that we all stick to our structure." (FG/2017)

In all three organizations, the initial responses followed our characterization of first-order learning and built on already flexible structural elements. Subsequently, however, these swift reactions were not sufficient to manage the crisis.

We therefore analyzed further structural changes over time (see also Table 5 in "Appendix").

The Red Cross was soon confronted with specific challenges beyond its emergency plans. Besides logistics, shelter and catering, there was a need for interpreters, psychosocial support, and for childcare for thousands of children. Besides, the Red Cross kept their core routine operations running (ambulances, emergency services). Therefore, a couple of second-order structural changes occurred: Volunteers autonomously organized psychosocial support and childcare, using social media, which was unprecedented in the organization. The Red Cross stuck to its emergency plan and lines of command, which enabled high flexibility regarding persons, thus new personnel, could be hired quickly, in large numbers and sometimes specific, new language skills (Arabic, Farsi). The organization temporarily loosened its strict procedure for recruiting volunteers. Furthermore, interviewees described 
a tendency of more autonomy for operating volunteers and the loosening of some bureaucratic rules. Nevertheless, the latter caused conflicts: "The HR managers did not understand and not accept to sign in new staff members three days later-as they work in the body of rules, this is central for their organization, because a rule is a rule and this makes it difficult." (FG 2017)

Caritas had always been very flexible in designing communication channels, adapting to new demands. This allowed for swift changes in structure. A new unit was founded for refugee emergency aid, an experienced executive quickly took over it's leadership, and new staff was hired. In the first few weeks, staff members from the various departments worked voluntarily with the refugees. Volunteer management became rather flexible, almost like in Train-of-Hope, yet without their geek-like deployment of social media. At one train station, "most people were external, ... only two to four experienced staff members, the rest completely new ... at peaks 150-200 volunteers per day." Guided by a strong mission, the organization was flexible in details of programs: "Suddenly we had a new error culture." (FG/2017) "Then we had two regimes in parallel, emergency care with completely different rules, and primary care with established standards and a completely different logic." (FG/2017) The management team was mainly on spot, thus strengthening their position and further motivating staff and volunteers. "Departmental boundaries blurred, hierarchic structures collapsed, staff members subverted the usual lines of command and support, internal committees and meeting structures were disrupted, because no one was there to attend." (CA/2016) Almost all of the second-order learning happened in the domain of flexible communication channels. On the other hand, new elements of redundancies were also implemented there, such as daily meetings of the two COOs and regular weekly meetings of representatives of all refugee aid projects. Apparently, those structural changes did not harm Caritas' routine operations in other fields. This might be due to high motivation and dedication to Caritas' mission.

Within just a few weeks-like in a pressure cookerTrain-of-Hope developed some redundancy in communication channels, such as the legal form of an association, a board of six members that took coordinative responsibilities and a number of specific units with coordinators, e.g., for children, infrastructure, social media, hygienic supply, and missing people. First, those units operated autonomously, loosely coupled, and coordination by the board was exceptional. Then, redundancy was increased step by step in all domains: scheduling volunteers, defining tasks, establishing communication channels. Nevertheless, Trainof-Hope was still described as flexible in communication channels and persons. Whoever came to the spot could define and take over tasks. The emergence of structure concerned primarily communication channels: founding an association, establishing units and a steering board, and starting cooperation with other CSOs. "So, we thought over the problems for two nights how to coordinate transport and interpretation, and then some areas were defined clearer and clearer, and coordinated, and then a real linking of the different stations emerged." (FG/2017). Besides the purpose and the concentration in one venue, strong personal bonds were still used as a basis for organizational changes. "We have our core team, people who have been there from the beginning. Without them, it would not work. ... If problems occur, we all sit together and talk-that helps." (TH/2016)

By March 2016, the influx of refugees had become significantly lower. Our interviews conducted in October 2016 and the focus groups conducted in 2017 aimed at a retrospective assessment of longer lasting organizational changes (see also Table 6 in "Appendix").

Among other second-order adaptations, the Red Cross had hired more additional staff to keep up routine operations and personnel with new competencies, too, mostly on a long-term basis. "Suddenly we had completely different people in our organization." (RC/2016) Also, it flexibly expanded fields of operation. Housing for asylum seekers, for example, was expanded from less than 100 persons attended before 2015 to a couple of thousand permanent slots. The Red Cross thus described increased program variety, which had been a domain of redundancy before. In the management control systems, something very different happened: During the crisis, control was relaxed. There was less paperwork and less reporting, because all resources were deployed to direct emergency aid. Control was substituted by trust. Meanwhile, there has been a backlash in control systems, and executives complain that reporting duties and paperwork are now more rigid than before 2015. These changes to programs and communication channels show that third-order learning obviously concerned also domains that had been quite redundant before.

Caritas reported third-order learning after the crisis, too. They developed emergency plans and started stockpiling (accommodations, garments, etc.) for upcoming events. They also founded a new unit for emergency aid, with staff and a budget that is completely flexible with regard to tasks and procedures. Further, many new persons have been kept in the organization, besides some of the volunteers also asylum seekers who want to engage voluntarily.

Yet, bureaucracy also rebounded at Caritas. Flexibility and trust, which helped Caritas to manage the crisis, were replaced by reporting rules, tolerance for ambiguity and failure was reduced, and learnings regarding procedures 
were secured: "I think we haven't been champions in this area, quality management, check lists, standards, care concepts, etc. We fundamentally thought over and concretized it, many things were developed, infrastructure, minimum standards, etc., so that we don't have to start all over again." (C/2016) Further, besides new offers for spontaneous and episodic volunteers also new rules for the cooperation with volunteers were established.

Planning for future emergencies increased: "We established a training curriculum. ... And we focus on our core competencies in emergency aid: caring and counseling." (FG/2017) Interviewees from Caritas are convinced that its structure proved viable during those exceptional months and that their staff's motivation had been outstanding but they also report long-term learning: "There is a new awareness for processes within Caritas, to distinguish between normal operations and emergency situations." (FG/2017)

A management team member reports that the joint experiences strengthened "meaning and trust in Caritas, its leadership, and the belief that we can handle even the worst." (CA/2016) Summing up, third-order learning at Caritas meant mainly increasing redundancy by tighter emergency programming and by changes in the communication channels. While Caritas' strategy as one of the redundant elements was not altered substantially but rather strengthened, long-term changes happened in the programming, but also in the organizational chart of Caritas. Thus, both stable and flexible domains of structure were subject to organizational learning.

Train-of-Hope is a singular case as its primary mission was accomplished by the end of the inflow of refugees. In December 2015, after having deployed thousands of volunteers and having delivered 300,000 work hours, Trainof-Hope shut down its operations at Vienna's main train station. The core team was reduced to four persons. Firstly, they decided not to terminate the organization, but to look for new fields of activities, all of them related to refugees: accommodation, language courses, and labor integration. Additionally, they reflected on their experiences by writing guidelines for comparable future situations and intensified planning for future programs. Yet, the further organizational strategy is still open, and the personal bonds have dissolved: "There was a good start, but then the struggles increased, between different groups, German courses, House of Hope, and there was a group for the statutes, because the old statutes didn't fit any more." (FG/2017) The conflict finally escalated, and by end of 2017, it was unclear whether the organization would survive: "Everything worked well onsite. But at the meta-level, at the board level, there were extreme differences, regarding the future direction." (FG/2017) Members could not agree on new goals and programs, and the communication channels built up in 2015 dissolved. The organization had secured its redundancy mainly by the strong purpose, the location, personal relationships, and by physical presence. In 2017 , Train-of-Hope's activities were no longer needed at this location, and the purpose was too narrow to guide new activities. Furthermore, presence had lost its importance, and with the start of conflicts between the actors, personal bonds eroded. The communication channels developed by second-order learning could not compensate this. Though this case is exceptional, it also shows that third-order learning occurred in the domains where the organization was originally redundant-in the programs and the communication structures. The breakdown of personal friendships and the fact that the purpose became obsolete accelerated the dissipation of structure.

To conclude, the analysis leads to the following assumptions regarding the relationship between organizational structure and responses to unexpected situations: Structure affects all stages of organizational responses and organizational learning. Initial responses preferably take place in dimensions where structure provides variety (firstorder learning). In addition, structural changes as a reaction to unexpected situations first mainly take place in dimensions where structure provides variety (second-order learning). If first- and second-order learning is not sufficient, structural changes will also take place in domains where structure provides redundancy (third-order learning), which might also result in the dissolution of organizations.

\section{Discussion and Limitations}

Prior research on organizational responses to crises has developed several categories, e.g., rebuttal, reorientation, evolution, and colonialization (Laughlin 1991); or established, extending, expanding, and emergent responses (Kreps and Bosworth 2007). Most of this work is grounded in organizational learning theories. Empirical research on organizational responses to the unexpected is still scarce and concentrates on team responses (Bechky and Okhuysen 2011) to rare events (Christianson et al. 2009; Weick 1993). Yet, it hardly explains how structural characteristics relate with different responses. Our research shall fill this gap.

The so-called refugee crisis of 2015 provides the empirical background for our analysis of organizational responses in relation to structure. We selected three CSOs with very different structures regarding redundancy and flexibility.

As a theoretical framework, we chose Luhmannian systems theory, in particular its concepts of organizational structure and decision premises: programs, communications channels, and persons. Though this theory is far from 
structural determinism, it claims that organizations will establish strategies and responses to unexpected events that are channeled by structural conditions perceived by decision makers of the organization. The self-reproducing nature of structures and routines makes them inherently resistant to externally imposed change (Grinyer and McKiernan 1992; Hendry and Seidl 2003). With this concept of decision premises, we combined and slightly reformulated the organizational learning framework to analyze responses and learning modes over time.

To secure their autopoiesis, organizations will not only oscillate between constraining and extending decision possibilities (Luhmann 2005), but they will do this guided by their specific balance of redundant and variable elements in their structure. In this vein, organizations will hesitate to relax redundant elements as long as they can respond in more flexible domains. To be open for change in one domain requires redundancy in others (see for the interplay between openness and closeness Dobusch et al. 2017)

Our findings widely support this theoretical assumption. The initial responses of CSOs were spectacular in Austria: Thousands of people were attended at borders or train stations; many emergency shelters were set up within days, thousands of volunteers were coordinated. Yet, those responses did not change the overall balance of redundancy and variety of the involved organizations. The Red Cross used its temporal flexibility to cope with the unexpected by means of quick reactions based on very clear programs, and an expansion of working hours. Caritas relied on its flexibility regarding hierarchy, other communication channels, and content; it thus also swiftly included unaffiliated, spontaneous volunteers. Train-of-Hope relied on a strong and narrow purpose, and on personal bonds to react very flexible with respect to communication channels, and the recruitment of new personnel.

In a second phase, structural adaptations also occurred in the domains of flexibility. The Red Cross kept its strict procedures but established restricted zones of autonomy for volunteers in certain task areas beyond the organization's core competencies. Additional staff members were recruited. Caritas utilized its flexibility of communication channels to allow for more spontaneous work, like temporal changes to hierarchic structures or meeting regulations, crucial roles, and responsibilities. A specific unit for emergency aid was founded, and at most sites, leadership roles for volunteers were established. Train-of-Hope kept its tight coupling on personal stability and purpose but implemented structural changes in communication channels by establishing new formal rules and a certain hierarchy.

In a third phase, after the urgency of the crisis had finally ceased, the organizations partly fell back into old routines. Most of the short-term and medium-term changes were temporary and did not affect the long-term balance of redundancy and variety. However, sustainable structural adaptations that affected formerly redundant domains were reported, too. At the Red Cross, parts of the new staff were kept permanently, and with the expansion into housing for asylum seekers, new content has been integrated permanently. Caritas also sustainably altered decision premises by introducing stricter emergency plans and by founding a new unit to serve as a very openly designed organizational reserve for unexpected crises. Interestingly, both organizations had eased control and bureaucracy at the peak of the crisis. Afterward, regulations were made even stricter than before. Train-of-Hope, which had managed a high workload due to stability in personal relations and a very strong and clear purpose, reduced personnel significantly, tried to change its field of activity, and finally drifted toward dissolution; in other words, it annihilated its domain of redundancy.

Our findings contribute to various strands of research. From an organizational learning perspective, our findings show that responses utilized all three levels of organizational learning. In their initial, first-order learning, the organizations relied on redundant elements of structure to secure their ability to act flexibly. Second-order learning happened only when first-order learning was not sufficient, and modifications to decision premises were enacted predominantly in domains where structure had allowed for flexibility before. Third-order learning, however, was triggered by the crisis, but not implemented until the organizations came into a quieter and steadier environment. Thus, we not only detected the forms of responses that the prior literature suggested (Kreps and Bosworth 2007; Laughlin 1991), but also some typical sequence in learning types.

Success and performance of CSOs are mainly a construction of stakeholders (Herman and Renz 1997). Nevertheless, during the so-called refugee crisis, all three organizations were rated to be quite successful in dealing with the unexpected-not only by our interviewees, but also by policy makers and a broader public (Kornberger et al. 2018). Therefore, in the first phase of a jolt, keeping the organization's particular balance of redundancy and variety might be a recommendable strategy, if not an inevitable consequence of organizational structure. Organizations were flexible where they were used to be flexible-and they protected the domains that ensured stability and security. In other words, when the world is turning upside down, organizations stick to their structural core competencies regarding redundancy and variety. Thus, what only at first sight seemed to be mere improvisation (e.g., Pina e Cunha et al. 2015), was somehow shaped by organizational structure. While unexpected jolts may work 
as unfreezing events for organizations (Carley and Harrald 1997), they did not unfreeze all elements, first and midrange reactions did not affect the stable domains of organizational decision premises.

Hence, organizations' capacity to respond to the unexpected relies on an appropriate interplay between flexibility and stability (Dobusch et al. 2017). While common sense would expect that organizations with flexible structures would be better prepared to react to jolts, we found that it was not flexibility alone that counts, but the type of flexibility. While it was also argued, that tightly coupled hierarchical organizations are better prepared for stressful situations (Bigley and Roberts 2001), we found that this might be only true if the organization had previously relied strongly on its hierarchy and the unexpected events fit in its conditional programs (Grothe-Hammer and Berthod 2017).

The prior literature has discussed whether unexpected events are opportunities for organizational learning (Carley and Harrald 1997), or rather, if their uniqueness impedes organizational learning (Starbuck 2009). We take a different standpoint in line with systems theory, as we argue that learning of organizations depends not so much on external incidents, but mainly on internal structure. While the external incident was more or less the same for all organizations, their responses were different. They did not primarily respond to this external incident, but to their internal way to understand it, process it, and respond to it.

Furthermore, one of our cases shows that third-order learning can terminate an organization. If essential domains of redundancy and stability are loosened with no stabilizing equivalent, the organization falls apart. Having accomplished the primary mission, third-order learning might include the dissolution of the organization.

Our results also support the view that improvisation depends on structure. In our cases, we have found all the activities and competencies identified as essential for improvisation by prior research (Bechky and Okhuysen 2011; Oliver and Roos 2003): role shifting, redundancy in task knowledge, reorganizing routines, reordering work, shared task knowledge, common workflow expectations, increased presence, creating a shared and emotionally grounded identity, and a shared set of guiding principles for action. Moreover, we show that these prerequisites for improvisation depend on the organizational decision premises. If persons in the form of leaders play a core role for redundancy, they must be physically present on site, as was the case with Caritas. If programs are crucial, e.g., in form of emergency plans, common workflow expectations and shared task knowledge guarantee effective improvisation, as was the case with the Red Cross. Role shifting and redundant task knowledge were especially important for Caritas and Train-of-Hope, because they had not developed plans and routines. Thus, we argue that improvisation relates to structural preconditions. Even in turbulent environments and in situations of dramatic change, organizational responses are basically self-referential.

Our research has many limitations. First, we analyzed only three cases. Though their selection was based on theoretical considerations, a caveat remains before generalizing and further research is needed. Second, notwithstanding our argumentation of second-order organizational observations and decisions by communicating with influential members, our methodology has limitations. Our case selection was not only inspired by theory but also by our first observations and interviews in 2015. Our findings, however, are strongly inspired by subsequent interviews and group discussions and thus by the descriptions of CSOs' decision makers. Nevertheless, the longitudinal research design allowed for valuable insights. Therefore, we hope that our investigation might serve to motivate further and more intensive research on the interplay of structure and organizational learning. In a world of rising complexity with a growing probability of crises, a deeper understanding of the coping strategies of organizations is important not only for organizational scholars, but also for practitioners.

Acknowledgments Open access funding provided by Vienna University of Economics and Business (WU).

Open Access This article is distributed under the terms of the Creative Commons Attribution 4.0 International License (http://crea tivecommons.org/licenses/by/4.0/), which permits unrestricted use, distribution, and reproduction in any medium, provided you give appropriate credit to the original author(s) and the source, provide a link to the Creative Commons license, and indicate if changes were made.

\section{Appendix}

See Table 3, 4, 5 and 6. 
Table 3 Intital structure-data sources and findings. Sources: Web-based documents (RC, Caritas), 13 interviews (2015), participant observation protocols (2015)

\begin{tabular}{|c|c|c|c|}
\hline & Programs & Communication channels & Persons \\
\hline \multicolumn{4}{|c|}{ Perceptions of initial structure } \\
\hline Red Cross & $\begin{array}{l}\text { Clear mission } \\
\text { Emergency plans } \\
\text { Standard routines }\end{array}$ & $\begin{array}{l}\text { Hierarchical } \\
\text { Incident-command oriented } \\
\text { Clear responsibilities } \\
\text { Defined rules for volunteers }\end{array}$ & $\begin{array}{l}\text { Flexible regarding the integration of } \\
\text { persons }\end{array}$ \\
\hline Caritas & $\begin{array}{l}\text { Strong and broad mission } \\
\text { History: clear political standpoint on } \\
\text { immigration }\end{array}$ & $\begin{array}{l}\text { Flat hierarchies } \\
\text { Flexibility regarding how to carry out } \\
\text { mission }\end{array}$ & $\begin{array}{l}\text { Charismatic leadership } \\
\text { Strong and accepted management } \\
\text { team } \\
\text { Shared values }\end{array}$ \\
\hline $\begin{array}{l}\text { Train-of- } \\
\text { Hope }\end{array}$ & $\begin{array}{l}\text { Clear purpose } \\
\text { Focus on one location }\end{array}$ & $\begin{array}{l}\text { Personal relations } \\
\text { Presence } \\
\text { Not formalized } \\
\text { No structure } \\
\text { Social media as constitutive for taking } \\
\text { part }\end{array}$ & $\begin{array}{l}\text { Initial group of friends } \\
\text { Very open relations to new volunteers }\end{array}$ \\
\hline
\end{tabular}

Criterion: mentioned by at least 2 sources

Elements safeguarding redundancy in bold letters

Table 4 First-order learning—data sources and findings. Sources: 13 interviews (2015), 5 field notes of participant observation

\begin{tabular}{|c|c|c|c|}
\hline & Programs & Communication channels & Persons \\
\hline \multicolumn{4}{|c|}{ Perceptions of first-order learning (initial responses) } \\
\hline $\begin{array}{l}\text { Red } \\
\text { Cross }\end{array}$ & $\begin{array}{l}\text { Activities followed mission and } \\
\text { emergency plans }\end{array}$ & $\begin{array}{l}\text { Applying standard routines } \\
\text { Strong hierarchy } \\
\text { Control structures } \\
\text { Little self-organization of volunteers }\end{array}$ & $\begin{array}{l}\text { Flexible regarding time and persons } \\
\text { Expansion of working hours } \\
\text { Activating of reserve army of } \\
\text { volunteers }\end{array}$ \\
\hline Caritas & $\begin{array}{l}\text { Taking over new tasks, based on } \\
\text { mission and history } \\
\text { Readjustment of strategic decisions } \\
\text { Caritas feeling }\end{array}$ & $\begin{array}{l}\text { Swift change in structure (new tasks forces, } \\
\text { hierarchies, responsibilities) } \\
\text { Self-organization of Volunteers (including } \\
\text { management tasks) } \\
\text { Rules for integration of volunteers suspended }\end{array}$ & $\begin{array}{l}\text { Strong and accepted leaders } \\
\text { Incorporation of many new volunteers } \\
\text { Trust among staff } \\
\text { Expansion of working hours based on } \\
\text { high motivation }\end{array}$ \\
\hline $\begin{array}{l}\text { Train-of- } \\
\text { Hope }\end{array}$ & $\begin{array}{l}\text { Day-to-day decisions oriented on } \\
\text { purpose } \\
\text { Focus on work not on structure } \\
\text { Task-pressure enhanced productivity }\end{array}$ & $\begin{array}{l}\text { Personal relationships and physical presence } \\
\text { crucial } \\
\text { Improvisation } \\
\text { No overall leadership } \\
\text { High external pressure } \\
\text { No hierarchy }\end{array}$ & $\begin{array}{l}\text { Individuals acted autonomously } \\
\text { Core team emerged } \\
\text { Completely open regarding new } \\
\text { persons }\end{array}$ \\
\hline
\end{tabular}

Criterion: mentioned by at least two sources

Decisions challenging domains of redundancy in bold letters 
Table 5 Second-order learning-data sources and findings. Sources: interviews with three top executives (2016)

\begin{tabular}{|c|c|c|c|}
\hline & Programs & Communication channels & Persons \\
\hline \multicolumn{4}{|c|}{ Perceptions of second-order learning (structural changes) } \\
\hline $\begin{array}{l}\text { Red } \\
\text { Cross }\end{array}$ & $\begin{array}{l}\text { New tasks (interpreters, psychosocial } \\
\text { support, childcare) }\end{array}$ & $\begin{array}{l}\text { Partial self-organization of volunteers } \\
\text { Use of social media } \\
\text { Partial relaxation of rules (e.g., regarding } \\
\text { recruiting) } \\
\text { Emergency plan and lines of command kept but } \\
\text { control relaxed }\end{array}$ & $\begin{array}{l}\text { Flexible integration of new (paid } \\
\text { and unpaid) staff } \\
\text { New types of personnel }\end{array}$ \\
\hline Caritas & $\begin{array}{l}\text { Strong mission kept but flexibility in } \\
\text { details of programs } \\
\text { New error culture }\end{array}$ & $\begin{array}{l}\text { New unit formed } \\
\text { New leaders (based on loosened requirements) } \\
\text { Flexible volunteer management } \\
\text { Blurring of departmental boundaries } \\
\text { Looser rules in emergency care } \\
\text { Lines of command flexibilized } \\
\text { The presence of management team } \\
\text { Daily meetings of involved staff }\end{array}$ & $\begin{array}{l}\text { New (paid and unpaid) staff } \\
\text { Integration of large numbers of } \\
\text { spontaneous volunteers }\end{array}$ \\
\hline $\begin{array}{l}\text { Train-of- } \\
\text { Hope }\end{array}$ & $\begin{array}{l}\text { No changes in location } \\
\text { Purpose further strengthened } \\
\text { Expansion of tasks in line with } \\
\text { mission }\end{array}$ & $\begin{array}{l}\text { Some formalization } \\
\text { Development of communication channels (to-do } \\
\text { lists, defined tasks responsibilities) } \\
\text { Strong personal bonds-core team }\end{array}$ & $\begin{array}{l}\text { Some formalization regarding } \\
\text { membership } \\
\text { Still very flexible regarding } \\
\text { persons }\end{array}$ \\
\hline
\end{tabular}

Criterion: Validated by group discussions (2017)

Changes concerning former domains of redundancy in bold letters

Table 6 Third-order learning_-data sources and findings. Sources: 3 focus group discussions (2017), related to interviews with top executives (2016)

Perceptions of third-order learning (longer lasting structural changes)

\begin{tabular}{|c|c|}
\hline \multirow{5}{*}{$\begin{array}{l}\text { Red } \\
\text { Cross }\end{array}$} & New tasks \\
\hline & $\begin{array}{l}\text { Significant expansion of some } \\
\text { fields of operation }\end{array}$ \\
\hline & New projects \\
\hline & Increased program variety \\
\hline & $\begin{array}{l}\text { Higher budgets for refugee } \\
\text { integration }\end{array}$ \\
\hline \multirow[t]{4}{*}{ Caritas } & New tasks \\
\hline & $\begin{array}{l}\text { Plans for future emergencies } \\
\text { (instead of broad mission) }\end{array}$ \\
\hline & Focus on core competencies \\
\hline & $\begin{array}{l}\text { New error culture and } \\
\text { standards }\end{array}$ \\
\hline \multirow{3}{*}{$\begin{array}{l}\text { Train- } \\
\text { of- } \\
\text { Hope }\end{array}$} & Primary task completed \\
\hline & Purpose lost \\
\hline & $\begin{array}{l}\text { Search for new fields of } \\
\text { activities }\end{array}$ \\
\hline
\end{tabular}

Backlash in control systems (standardized briefings, checklists, instruments for cooperation)

Strengthened cooperation with other organizations in the field

New distribution of staff between departments

New completely flexible unit for future crises

Stronger bureaucracy (rules for reporting, cooperation with volunteers)

New organization units

Closing units

Guidelines for comparable situations developed

Personal bonds dissolved

Conflicts about power relations, statutes, regulation
New type of personnel—competencies, origin, experiences ("crises-hoppers")

New staff on long-term basis

Strengthened meaning, trust, bonds Many asylum seekers engage voluntarily Some volunteers kept for different fields New staff on long-term basis

Most volunteers left

Emotionalization of relations

Criterion: consensus

Changes concerning former domains of redundancy in bold letters 


\section{References}

Argyris, C., \& Schön, D. (1978). Organizational learning I: A theory of action perspective. Reading, MA: Addisson-Wesley.

Argyris, C., \& Schön, D. (1996). Organizational learning II: Theory, method, and practice. Reading, MA: Addisson-Wesley.

Bakken, T., \& Hernes, T. (Eds.). (2003). Autopoietic organization theory: Drawing on Niklas Luhmann's social system perspective. Copenhagen: Copenhagen Business School Press.

Barrett, F. J. (1998). Coda: Creativity and improvisation in jazz and organizations: Implications for organizational learning. Organization Science, 9(5), 605-622.

Bateson, G. (1972). Steps to an ecology of mind: Collected essays in anthropology, psychiatry, evolution, and epistemology. Chicago: University of Chicago Press.

Bechky, B. A., \& Okhuysen, G. A. (2011). Expecting the unexpected? How SWAT officers and film crews handle surprises. Academy of Management Journal, 54(2), 239-261.

Besio, C., \& Pronzini, A. (2011). Inside organizations and out: Methodological tenets for empirical research inspired by systems theory. Historical Social Research, 36(1), 18-41. https://doi.org/ 10.12759/hsr.36.2011.1.18-41.

Bigley, G. A., \& Roberts, K. H. (2001). The incident command system: High-reliability organizing for complex and volatile task environments. The Academy of Management Journal, 44(6), 1281-1299.

Boyatzis, R. E. (1998). Transforming qualitative information: Thematic analysis and code development. London: Sage.

Carley, K. M., \& Harrald, J. R. (1997). Organizational learning under fire. The American Behavioral Scientist, 40(3), 310-332.

Chiva, R., \& Habib, J. (2015). A framework for organizational learning: Zero, adaptive and generative learning. Journal of Management and Organization, 21(3), 350-368.

Christianson, M. K., Farkas, M. T., Sutcliffe, K. M., \& Weick, K. E. (2009). Learning through rare events: Significant interruptions at the Baltimore \& Ohio Railroad Museum. Organization Science, 20(5), 846-860.

Clegg, S. (2015). Back in the USSR: Introducing recursive contingency into institutional theory. Organization Studies, 36(1), 73-90.

Cooke, D. L., \& Rohleder, T. R. (2006). Learning from incidents: From normal accidents to high reliability. System Dynamics Review, 22(3), 213-239.

Cornelissen, J. P. (2006). Making sense of theory construction: Metaphor and disciplined imagination. Organization Studies, 27(11), 1579-1597.

Crossan, M. M., Lane, H. W., \& White, R. E. (1999). An organizational learning framework: From intuition to institution. Academy of Management Review, 24(3), 522-537.

Crossan, M. M., Maurer, C., \& White, R. E. (2011). Reflections on the 2009 AMR decade award: Do we have a theory of organizational learning? Academy of Management Review, 36(3), 446-460.

Dobusch, L., Dobusch, L., \& Müller-Seitz, G. (2017). Closing for the benefit of openness? The case of Wikimedia's open strategy process. Organization Studies. https://doi.org/10.1177/ 0170840617736930 .

Dobusch, L., \& Schoeneborn, D. (2015). Fluidity, identity, and organizationality: The communicative constitution of anonymous. Journal of Management Studies, 52(8), 1005-1035.

Eisenhardt, K. M., \& Graebner, M. E. (2007). Theory building from cases: Opportunities and challenges. Academy of Management Journal, 50(1), 25-32.

Eisenhardt, K. M., \& Martin, J. A. (2000). Dynamic capabilities: What are they? Strategic Management Journal, 21(10-11), $1105-1121$.
Fereday, J., \& Muir-Cochrane, E. (2006). Demonstrating rigor using thematic analysis: A hybrid approach of inductive and deductive coding and theme development. International Journal of Qualitative Methods, 5(1), 80-92.

Ferreira, S. (2014). Sociological observations of the third sector through systems theory: An analytical proposal. VOLUNTAS: International Journal of Voluntary and Nonprofit Organizations, 25(6), 1671-1693.

Fiol, C. M., \& Lyles, M. A. (1985). Organizational learning. Academy of management review, 10(4), 803-813.

Gibson, C. B., \& Birkinshaw, J. (2004). The antecedents, consequences, and mediating role of organizational ambidexterity. The Academy of Management Journal, 47(2), 209-226.

Greenwood, R., \& Hinings, C. R. (1987). Editorial introduction: Organizational transformations. Journal of Management Studies, 24(6), 561-564.

Greenwood, R., \& Hinings, C. R. (1988). Organizational design types, tracks and the dynamics of strategic change. Organization Studies, 9(3), 293-316.

Greenwood, R., \& Hinings, C. R. (1993). Understanding strategic change: The contribution of archetypes. Academy of Management Journal, 33(5), 725-755.

Greenwood, R., \& Hinings, C. R. (1996). Understanding radical organizational change: Bringing together the old and the new institutionalism. Academy of Management Review, 21(4), 1022-1054.

Grinyer, P., \& McKiernan, P. (1992). Typologies of corporate recovery. In P. Barrar \& C. L. Cooper (Eds.), Managing organisations in 1992 (pp. 131-158). London: Routledge.

Grothe-Hammer, M., \& Berthod, O. (2017). The programming of decisions for disaster and emergency response: A Luhmannian approach. Current Sociology, 65(5), 735-755.

Hadida, A. L., Tarvainen, W., \& Rose, J. (2015). Organizational improvisation: A consolidating review and framework. International Journal of Management Reviews, 17(4), 437-459.

Hamel, G., \& Valikangas, L. (2003). The quest for resilience. Harvard Business Review, 81(9), 52-65.

He, Z.-L., \& Wong, P.-K. (2004). Exploration vs. exploitation: An empirical test of the ambidexterity hypothesis. Organization Science, 15(4), 481-494.

Hendry, J., \& Seidl, D. (2003). The structure and significance of strategic episodes: Social systems theory and the routine practices of strategic change. Journal of Management Studies, 40(1), 175-196.

Herman, D. R., \& Renz, D. O. (1997). Multiple constituencies and the social construction of nonprofit organization effectiveness. Nonprofit and Voluntary Sector Quarterly, 26(2), 185-206.

Holmer-Nadesan, M. (1997). Essai: Dislocating (instrumental) organizational time. Organization Studies, 18(3), 481-510.

Kornberger, M., Leixnering, S., Meyer, R. E., \& Höllerer, M. (2018). Rethinking the sharing economy: The nature and organization of sharing in the 2015 refugee crisis. Academy of Management Discoveries, published online before print.

Kreps, G. A., \& Bosworth, S. L. (1993). Disaster, organizing, and role enactment: A structural approach. The American Journal of Sociology, 99(2), 428.

Kreps, G. A., \& Bosworth, S. L. (2007). Organizational adaptation to disaster, handbook of disaster research (pp. 297-315). New York, NY: Springer.

Laughlin, R. C. (1991). Environmental disturbances and organizational transitions and transformations: Some alternative models. Organization Studies, 12(2), 209.

Lindell, M. K. (2013). Disaster studies. Current Sociology, 61(5-6), $797-825$.

Lissack, M. R., \& Letiche, H. (2002). Complexity, emergence, resilience, and coherence: Gaining perspective on organizations 
and their study. Emergence: A Journal of Complexity Issues in Organizations and Management, 4(3), 72-94.

Luhmann, N. (1984). Soziale systeme. Frankfurt: Grundriß einer allgemeinen Theorie, Suhrkamp.

Luhmann, N. (1986). The autopoiesis of social systems. In F. Geyer \& J. van der Zouwen (Eds.), Sociocybernetic paradoxes: Observation, control and evolution of self-steering systems (pp. 171-192). London: Sage.

Luhmann, N. (1988). Organisation. In W. Küpper \& G. Ortmann (Eds.), Mikropolitik (pp. 165-185). Opladen: Westdeutscher Verlag.

Luhmann, N. (1998). Die Gesellschaft der Gesellschaft. Frankfurt am Main: Suhrkamp.

Luhmann, N. (2000). Organisation und Entscheidung. Opladen/ Wiesbaden.

Luhmann, N. (2003). Organization. In T. Bakken \& T. Hernes (Eds.), Autopoietic organization theory: Drawing on Niklas Luhmann's social systems perspective (pp. 31-52). Copenhagen: Abstrakt/ Liber/Copenhagen Business School Press.

Luhmann, N. (2005). The paradox of decision making. In D. Seidl \& K. H. Becker (Eds.), Niklas Luhmann and organization studies (pp. 85-107). Copenhagen: Copenhagen Business School Press.

Luhmann, N. (2006). System as difference. Organization, 13(1), $37-57$.

Luhmann, N. (2012). Theory of society. Stanford: Stanford University Press.

Madsen, P. M. (2009). These lives will not be lost in vain: Organizational learning from disaster in U.S. coal mining. Organization Science, 20(5), 861-875.

March, J. G. (1991). Exploration and exploitation in organizational learning. Organization Science, 2(1), 71-87.

Meyer, A. D. (1982). Adapting to environmental jolts. Administrative Science Quarterly, 27(4), 515-537.

Miles, M. B., Huberman, A. M., \& Saldaña, J. (2014). Qualitative data analysis: A methods sourcebook (3rd ed.). Los Angeles: SAGE Publications.

Moorman, C., \& Miner, A. S. (1998). Organizational improvisation and organizational memory. Academy of Management Review, 23(4), 698-723.

Oliver, D., \& Roos, J. (2003). Dealing with the unexpected: Critical incidents in the LEGO Mindstorms team. Human Relations, 56(9), 1057-1081.

Onwuegbuzie, A. J., \& Leech, N. L. (2007). A call for qualitative power analyses. Quality \& Quantity, 41(1), 105-121.

Pina e Cunha, M., Neves, P., Clegg, S. R., \& Rego, A. (2015). Tales of the unexpected: Discussing improvisational learning. Management Learning, 46(5), 511-529.
Pugh, D. S., Hickson, D. J., Hinings, C. R., \& Turner, C. (1968). Dimensions of organization structure. Administrative Science Quarterly, 13(1), 65-105.

Schoeneborn, D. (2011). Organization as communication: A Luhmannian perspective. Management Communication Quarterly, 25(4), 663-689.

Schütz, A. (1974). Der sinnhafte Aufbau der sozialen Welt. Frankfurt: Eine Einleitung in die verstehende Soziologie, Suhrkamp.

Seidl, D., \& Becker, K. H. (2006). Organizations as distinction generating and processing systems: Niklas Luhmann's contribution to organization studies. Organization, 13(1), 9-35.

Simsa, R. (2017). Leaving emergency management in the refugee crisis to civil society? The case of Austria. Journal of Applied Security Research, 12(1), 78-95.

Simsa, R., Rameder, P., Aghamanoukjan, A., \& Totter, M. (2018). Spontaneous volunteering in social crises: Self-organization and coordination. Nonprofit and Voluntary Sector Quarterly, 0899764018785472.

Starbuck, W. H. (2009). Cognitive reactions to rare events: Perceptions, uncertainty, and learning. Organization Science, 20(5), 925-937.

Starbuck, W. H., \& Farjoun, M. (2009). Organization at the limit: Lessons from the Columbia disaster. New Jersey: Wiley.

Sutcliffe, K. M., \& Vogus, T. J. (2003). Organizing for resilience. In K. Cameron, J. E. Dutton, \& R. E. Quinn (Eds.), Positive organizational scholarship (pp. 94-110). San Francisco: BerrettKoehler.

Twigg, J., \& Steiner, D. (2002). Mainstreaming disaster mitigation: Challenges to organisational learning in NGOs. Development in Practice, 12, 473-479.

Välikangas, L. (2010). The resilient organization. How adaptive cultures thrive even when strategy fails. New York: McGrawHill.

Weick, K. E. (1993). The collapse of sensemaking in organizations: The Mann Gulch disaster. Administrative Science Quarterly, $38(4), 628-652$

Weick, K. E., \& Sutcliffe, K. M. (2011). Managing the unexpected: Resilient performance in an age of uncertainty. New Jersey: Wiley.

Whittaker, J., McLennan, B., \& Handmer, J. (2015). A review of informal volunteerism in emergencies and disasters: Definition, opportunities and challenges. International Journal of Disaster Risk Reduction, 13, 358-368.

Zollo, M., \& Winter, S. G. (2002). Deliberate learning and the evolution of dynamic capabilities. Organization Science, 13(3), 339-351. 